\title{
Case Report \\ Endovascular Repair of Aortobronchial Fistula due to Saccular Aneurysm of Thoracic Aorta
}

\author{
Konstantinos Tigkiropoulos, Kyriakos Stavridis, Ioannis Lazaridis, and Nikolaos Saratzis \\ Vascular Unit, 1st University Department of Surgery, Aristotle University of Thessaloniki, Papageorgiou General Hospital, \\ Thessaloniki, Greece \\ Correspondence should be addressed to Konstantinos Tigkiropoulos; kostastig@yahoo.com
}

Received 25 September 2017; Accepted 9 November 2017; Published 27 November 2017

Academic Editor: Nilda Espinola-Zavaleta

Copyright (C) 2017 Konstantinos Tigkiropoulos et al. This is an open access article distributed under the Creative Commons Attribution License, which permits unrestricted use, distribution, and reproduction in any medium, provided the original work is properly cited.

\begin{abstract}
Aortobronchial fistula $(\mathrm{ABF})$ is a rare condition which can be lethal if left untreated. Open surgical treatment carries high morbidity and mortality. Recent advances in endovascular technology have made thoracic endovascular aortic repair (TEVAR) the treatment of choice. We present a successful endovascular repair of aortobronchial fistula due to a saccular aneurysm of descending thoracic aorta.
\end{abstract}

\section{Introduction}

Aortobronchial fistulas are communications between the thoracic aorta and the adjacent pulmonary parenchyma or tracheobronchial tree. The causes include aortic aneurysms, pseudoaneurysms, traumatic thoracic aorta injuries, penetrating aortic ulcers, and previous thoracic aortic surgery [13]. Intermittent or massive haemoptysis is the main symptom, but it is nonspecific and high index of suspicion is necessary to diagnose $\mathrm{ABF}$. Conventional open surgical treatment was the treatment of choice for many years and is associated with increased morbidity and mortality with the latter ranging from 15 to $41 \%[1,4]$. Recent advances in endovascular technology have made TEVAR the treatment of choice, with success rate of $90 \%$ and in-hospital mortality of $3 \%$, for multiple aortic pathologies including aneurysms, dissections, traumatic aortic injuries, and aortobronchial as well as aortoesophageal fistulae [5]. We present the successful repair of an $\mathrm{ABF}$ in a patient using endoluminal self-expandable stent grafts.

\section{Case Report}

A 64-year-old male presented to the emergency with a massive heamoptysis. He had a history of interscapular pain and intermittent haemoptysis the last five days. Laboratory values were normal apart from hematocrit $(\mathrm{Hct}=26 \%)$. An urgent computer tomography (CT) with intravenous contrast was performed which showed a $5,5 \mathrm{~cm}$ saccular aneurysm of the descending thoracic aorta arising less than $2 \mathrm{~cm}$ from the left subclavian artery and intrapulmonary hematoma (Figures 1 and 2). Preoperative bronchoscopy was avoided since it could provoke an intrapulmonary bleeding which could be fatal. Immediate consult for vascular surgery was called.

The procedure was carried out in a fully equipped operation theatre under spinal anaesthesia. Surgical access was gained through common femoral arteries in standard surgical fashion. The patient was systematically heparinized (75 units/kg). A Terumo guidewire (Terumo Corporation, Tokyo, Japan) was inserted through the right common femoral artery to the ascending aorta which was exchanged with a 0.035 Backup Meier (Boston Scientific, USA) stiff wire. An 8F-60 cm arrow (Arrow International, Inc., Reading, PA, USA) was advanced through the left common femoral artery to the descending thoracic aorta. An aortography was performed which revealed the saccular aneurysm just distal to the left subclavian artery (Figure 3). An Ankura (Lifetech Scientific; Maastricht, Netherland) endovascular stent graft with 


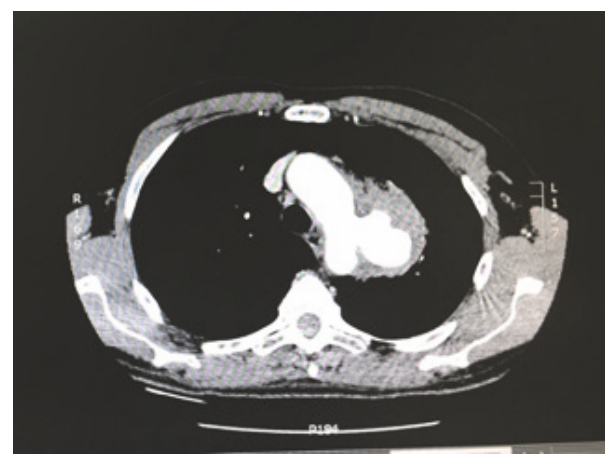

FIGURE 1: CT with intravenous contrast showed a $5,5 \mathrm{~cm}$ saccular aneurysm of descending thoracic aorta.

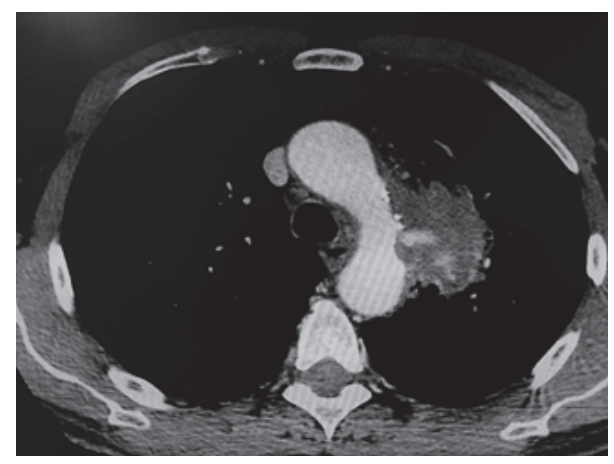

FIGURE 2: CT depicted an aortobronchial fistula with intrapulmonary hematoma.

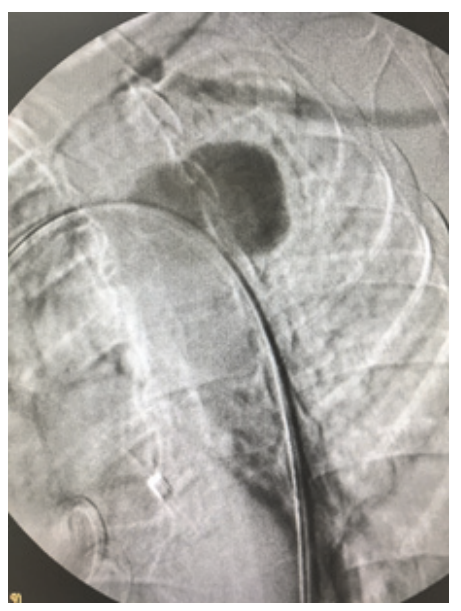

FIGURE 3: DSA revealed the presence of pseudoaneurysm just distal to the left subclavian artery.

$40 \mathrm{~mm}$ diameter and $16 \mathrm{~cm}$ length was deployed under fluoroscopic control. Completion arteriogram was performed with exclusion of the saccular aneurysm, coverage of the left subclavian artery, and absence of endoleak (Figure 4).

The patient had an excellent recovery with no signs of arm ischemia postoperatively. He was discharged after 7 days under a single antiplatelet therapy (clopidogrel) and a broad spectrum antibiotic therapy (moxifloxacin) for at least

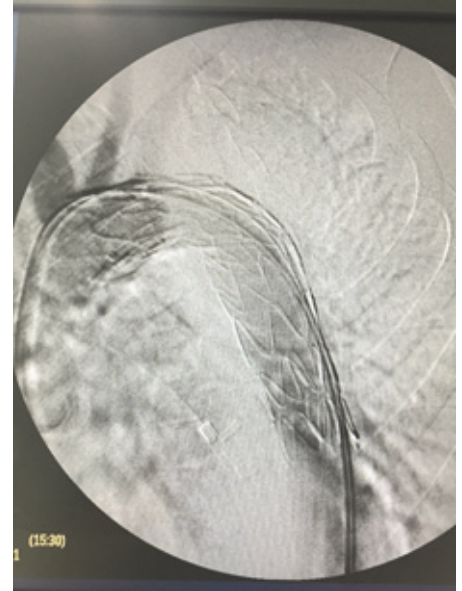

FIgURE 4: Deployment of Ankura endograft with exclusion of the saccular aneurysm, coverage of the left subclavian artery, and absence of endoleak.

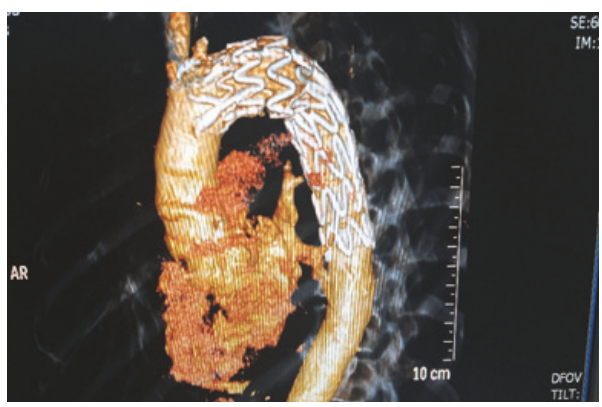

FIGURE 5: Three-dimensional CT angiography of thoracic aorta with proper placement of endograft and occlusion of left subclavian artery.

3 months. A follow-up CT angiography revealed accurate placement of endograft with no endoleak and thrombosis of the saccular aneurysm (Figure 5). A PET scan with 8 fluorodeoxyglucose was performed 1 month postoperatively which was negative for endograft infection.

\section{Literature Review}

A systematic review by Riesenman et al. at 2009 [6] reported published case reports and case series of endovascular repair of aortobronchial fistulas. Sixty-five patients were treated with stent graft deployment. Most of the patients (55\%) had previously undergone thoracic aortic surgery, and of these 36 patients $14(39 \%)$ had undergone the initial aortic operation for aneurysms or pseudoaneurysm of the descending thoracic aorta and 13 (36\%) for congenital aortic coarctation. A commercially manufactured thoracic endograft was deployed in $75 \%$ of patients and reintervention was performed in 8 patients, 7 of these in less than 30 days from the procedure.

Canaud et al. provided a systematic review of outcomes of thoracic endovascular repair for aortobronchial fistula [7]. One hundred thirty-four patients were identified. TEVAR was performed within 24 hours in $84.8 \%$ of the patients. 
Overall 30-day mortality was 5.9\%, endovascular leak was the main complication, and recurrence of $\mathrm{ABF}$ was observed in 14 patients (11.1\%). Midterm outcomes (after 30 days) included all-cause and aortic related mortality which were $21.4 \%$ and $14.3 \%$, respectively.

\section{Discussion}

Aortobronchial fistula $(\mathrm{ABF})$ is a potentially serious condition which can be lethal if it is not diagnosed or left untreated $[2,4]$. Most of the times it is difficult to diagnose but a high index of suspicion is essential in patients with a known history or previously treated thoracic aortic pathology. Various imaging techniques can assist in the diagnosis of $\mathrm{ABF}$. Computed tomography angiography (CTA) is the imaging technique of choice due to its accuracy and speed [8]. The cardinal symptom is haemoptysis, intermittent or massive, which may be fatal $[9,10]$.

Once diagnosis of $\mathrm{ABF}$ has been established prompt intervention is vital. Open surgical repair was the mainstay of treatment for decades; however it is associated with high morbidity and mortality due to the need for emergent operation in patients with multiple comorbidities, reoperative thoracic aortic exposure, possible cardiopulmonary bypass, and aortic cross clamping $[2,11]$. Picichè et al. provided a review of specifically postoperative aortobronchopulmonary fistulas. Seventy-six patients were identified with a total of 79 fistulas. Open surgical procedures were used in 50 fistulas with a mortality rate of $16 \%$, most of them dying intraoperatively. In the group of patients ( $n: 15)$ who were treated endovascularly there was not any death intraoperatively and author concluded that endovascular treatment was the proper therapy [12].

TEVAR has become the treatment of choice for multiple aortic pathologies including ABFs with low rates of mortality, $3 \%$, shorter hospitalization in the intensive care unit, and faster rehabilitation [5]. However, due to its rarity, experience with endovascular repair is limited and outcomes have been reported to small case series or isolated case reports [13-22]. Further studies are needed to determine its long term efficacy and safety.

\section{Consent}

The patient has consented for publication of case report.

\section{Conflicts of Interest}

The authors declare that they have no conflicts of interest.

\section{References}

[1] C. J. Bailey, S. Force, R. Milner, K. Kasirajan, and R. K. Veeraswamy, "Thoracic endovascular repair as a safe management strategy for aortobronchial fistulas," Journal of Vascular Surgery, vol. 53, no. 5, pp. 1202-1209, 2011.

[2] S.-F. Liu, Y.-C. Chen, M.-C. Lin, and C.-L. Kao, "Thoracic aortic aneurysm with aortobronchial fistula: a thirteen-year experience," Heart \& Lung: The Journal of Acute and Critical Care, vol. 33, no. 2, pp. 119-123, 2004.

[3] L. K. Von Segesser, T. Tkebuchava, U. Niederhäuser et al., "Aortobronchial and aortoesophageal fistulae as risk factors in surgery of descending thoracic aortic aneurysms," European Journal of Cardio-Thoracic Surgery, vol. 12, no. 2, pp. 195-201, 1997.

[4] E. L. MacIntosh, J. C. W. Parrott, and H. W. Unruh, "Fistulas between the aorta and traceobronchial tree," The Annals of Thoracic Surgery, vol. 51, no. 3, pp. 515-519, 1991.

[5] F. H. Jonker, F. J. Schlösser, F. L. Moll et al., "Outcomes of thoracic endovascular aortic repair for aortobronchial and aortoesophageal fistulas," Journal of Endovascular Therapy, vol. 16, no. 4, pp. 428-440, 2009.

[6] P. J. Riesenman, J. D. Brooks, and M. A. Farber, “Thoracic endovascular aortic repair of aortobronchial fistulas," Journal of Vascular Surgery, vol. 50, no. 5, pp. 992-998, 2009.

[7] L. Canaud, B. A. Ozdemir, S. Bahia, R. Hinchliffe, I. Loftus, and M. Thompson, "Thoracic endovascular aortic repair for aortobronchial fistula," The Annals of Thoracic Surgery, vol. 96, no. 3, pp. 1117-1121, 2013.

[8] C. L. Foster, C. L. Kalbhen, T. C. Demos, and V. A. Lonchyna, "Aortobronchial fistula occurring after coarctation repair: findings on aortography, helical CT, and CT angiography," American Journal of Roentgenology, vol. 171, no. 2, pp. 401-402, 1998.

[9] C.-L. Tsai, W.-T. Chang, and W.-J. Chen, "Hemoptysis caused by aortobronchial fistula," The American Journal of Emergency Medicine, vol. 22, no. 6, pp. 499-501, 2004.

[10] R. Oppenheimer and L. Brotherton, "Aortobronchial fistula: a rare etiology for hemoptysis," Ear, Nose and Throat Journal, vol. 81, no. 4, pp. 257-259, 2002.

[11] M. Picichè, R. De Paulis, A. Fabbri, and L. Chiariello, "Postoperative aortic fistulas into the airways: etiology, pathogenesis, presentation, diagnosis, and management," The Annals of Thoracic Surgery, vol. 75, no. 6, pp. 1998-2006, 2003.

[12] M. Picichè, R. G. Demaria, and B. Albat, "Endovascular repair of postoperative aortobronchopulmonary fistulas," The Journal of Thoracic and Cardiovascular Surgery, vol. 133, no. 4, p. 1125, 2007.

[13] T. A. Chuter, K. Ivancev, B. Lindblad et al., "Endovascular stentgraft exclusion of an aortobronchial fistula," Journal of Vascular and Interventional Radiology, vol. 7, no. 3, pp. 357-359, 1996.

[14] A. C. Campagna, J. H. Wehner, C. M. Kirsch et al., "Endovascular stenting of an aortopulmonary fistula presenting with hemoptysis. A case report," Journal of Cardiovascular Surgery, vol. 37, pp. 643-646, 1996.

[15] R. Karmy-Jones, C. A. Lee, S. C. Nicholls, and E. Hoffer, "Management of aortobronchial fistula with an aortic stentgraft," Chest, vol. 116, no. 1, pp. 255-257, 1999.

[16] J. M. Caiati, M. L. Marin, R. M. Flores, C. R. Smith, E. C. Martin, and G. J. Todd, "Endovascular management of an aortobronchial fistula arising after resection of a primary aortic sarcoma: a case report," Vascular and Endovascular Surgery, vol. 35, no. 1, pp. 73-79, 2001.

[17] J.-H. Yoo, C.-T. Lee, Y.-S. Shim, J. W. Chung, H. Ahn, and K. W. Kim, "Aortobronchial fistula presenting as recurrent hemoptysis and successfully treated with an endovascular stent graft," Respiration, vol. 68, no. 5, pp. 537-539, 2001.

[18] N. Kotzampassakis, P. Delanaye, F. Masy, and E. Creemers, "Endovascular stent-graft for thoracic aorta aneurysm caused by Salmonella," European Journal of Cardio-Thoracic Surgery, vol. 26, no. 1, pp. 225-227, 2004. 
[19] F. Numan, H. Arbatli, N. Yagan et al., "Endovascular treatment of an aortobronchial fistula," CardioVascular and Interventional Radiology, vol. 27, no. 1, pp. 71-73, 2004.

[20] A. Saratzis, N. Saratzis, D. Fillipou, N. Melas, and D. Kiskinis, "Endovascular stent-graft repair of an aortobronchial fistula: case report and review of the literature," European Journal of Vascular and Endovascular Surgery, vol. 9, no. 6, pp. 123-125, 2005.

[21] N. Ashida-Urata, T. Nomura, H. Kamiya, and N. Keira, "Hemoptysis is a critical sign of aortobronchial fistula," Internal Medicine, vol. 56, no. 19, pp. 2683-2684, 2017.

[22] M. Sakai, Y. Ozawa, T. Nakajima, A. Ikeda, T. Konishi, and K. Matsuzaki, "Thick lung wedge resection for acute lifethreatening massive hemoptysis due to aortobronchial fistula," Journal of Thoracic Disease, vol. 8, no. 9, pp. E957-E960, 2016. 


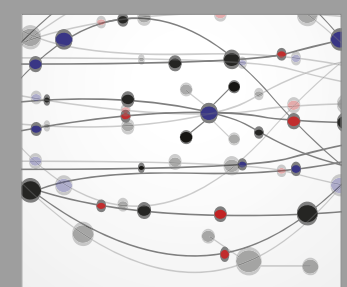

The Scientific World Journal
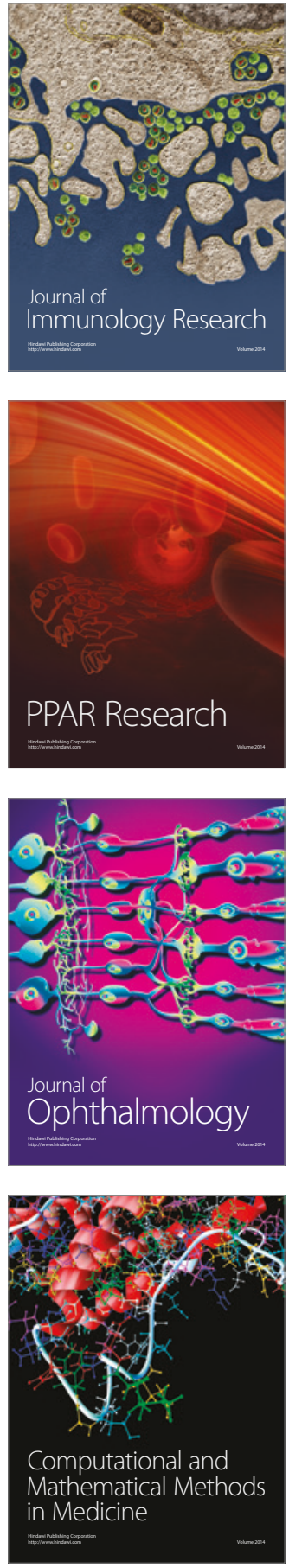

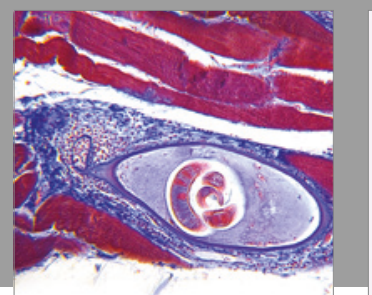

Gastroenterology Research and Practice
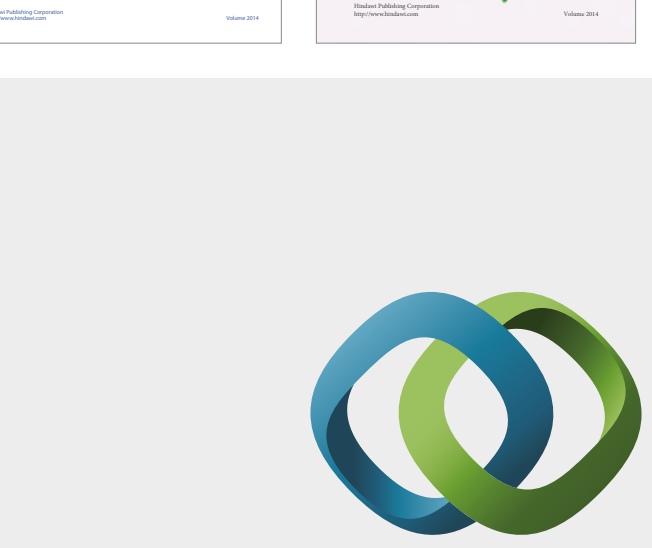

\section{Hindawi}

Submit your manuscripts at

https://www.hindawi.com
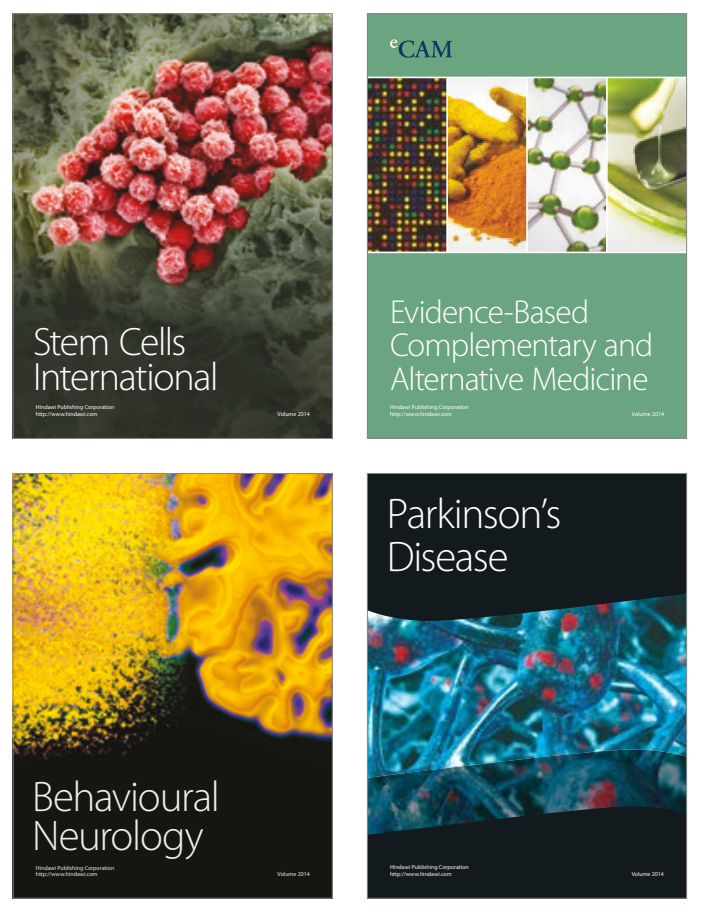
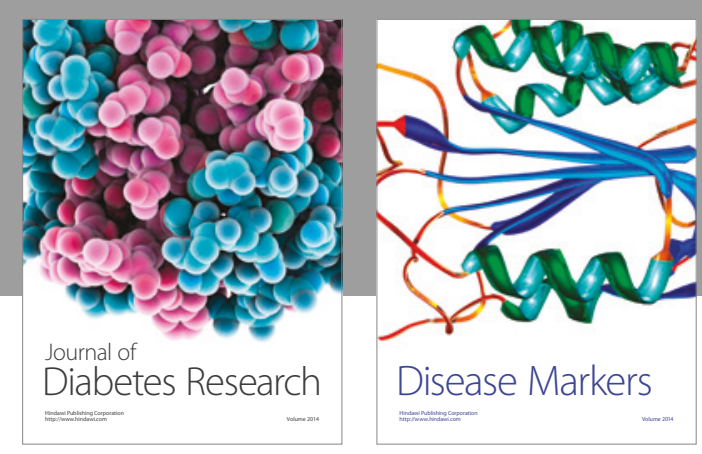

Disease Markers
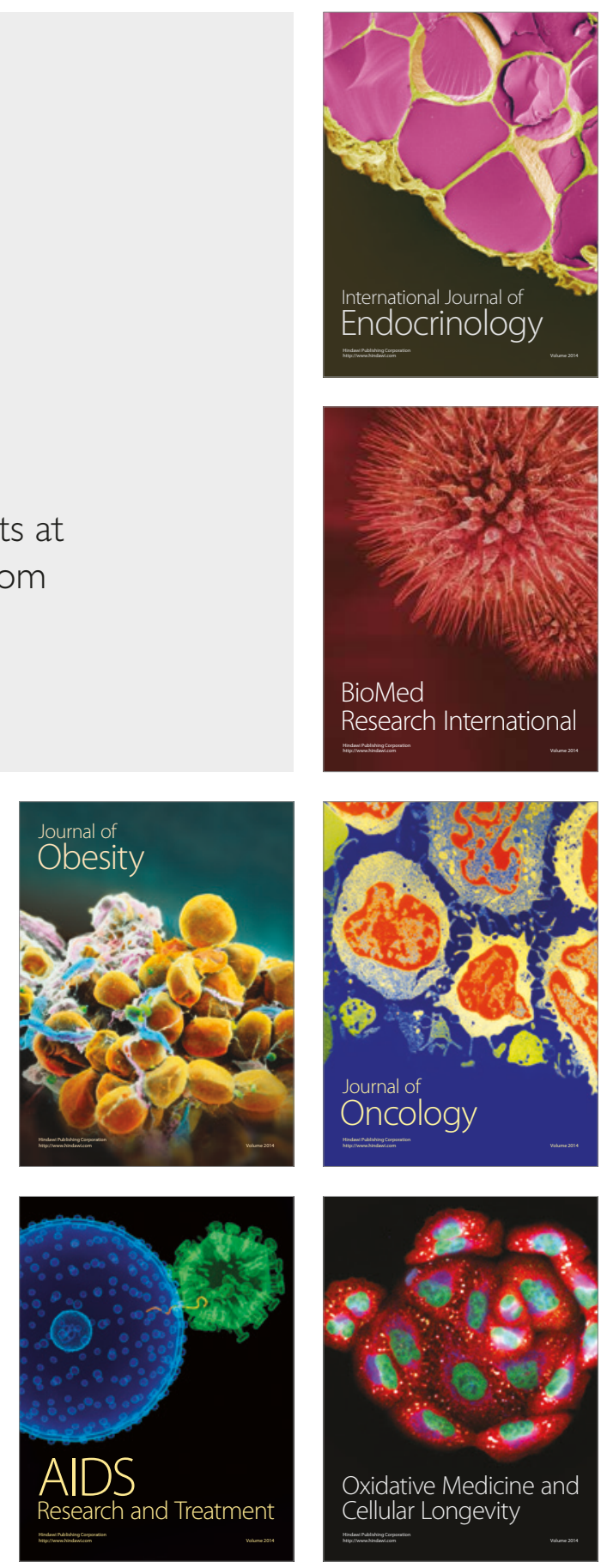